\section{POS0271-HPR PATIENT PERSPECTIVE ON A DRUG SAFETY MONITORING SYSTEM FOR IMMUNE-MEDIATED INFLAMMATORY DISEASES BASED ON PATIENT- REPORTED OUTCOMES}

L. Kosse ${ }^{1}$, G. Weits ${ }^{1}$, H. Vonkeman ${ }^{2,3}$, S. Tas ${ }^{4}$, F. Hoentjen ${ }^{5}$, M. Van Doorn ${ }^{6}$, P. Spuls ${ }^{7}$, G. D'haens ${ }^{8}$, M. Nurmohamed ${ }^{9}$, E. Van Puijenbroek ${ }^{10,11}$, B. Van den Bemt ${ }^{12,13}$, N. Jessurun ${ }^{1} .{ }^{1}$ Netherlands Pharmacovigilance Centre Lareb, Monitoring, 's-Hertogenbosch, Netherlands; ${ }^{2}$ Medisch Spectrum Twente, Rheumatology, Enschede, Netherlands; ${ }^{3}$ University of Twente, Psychology, Health \& Technology, Enschede, Netherlands; ${ }^{4}$ Amsterdam UMC, location Academic Medical Center, University of Amsterdam, Amsterdam Infection \& Immunity Institute and Amsterdam Rheumatology \& Immunology Center (ARC), Rheumatology \& Clinical Immunology, Amsterdam, Netherlands; ${ }^{5}$ Radboudumc, Gastroenterology, Nijmegen, Netherlands; ${ }^{6}$ Erasmus MC, Dermatology, Rotterdam, Netherlands: ${ }^{7}$ Amsterdam UMC, Amsterdam Public Health, Immunity and Infections, University of Amsterdam, Dermatology, Amsterdam, Netherlands; ${ }^{8}$ Amsterdam UMC, location Academic Medical Center, University of Amsterdam, Gastroenterology, Amsterdam, Netherlands; ${ }^{9}$ Reade and Amsterdam Rheumatology \& Immunology Center (ARC), Rheumatology, Amsterdam, Netherlands: ${ }^{10}$ Netherlands Pharmacovigilance Centre Lareb, Signal detection, 's-Hertogenbosch, Netherlands; ${ }^{11}$ University of Groningen, Groningen Research Institute of Pharmacy, PharmacoTherapy, Epidemiology \& Pharmacoeconomics, Groningen, Netherlands; ${ }^{12}$ Radboudumc, Pharmacy, Nijmegen, Netherlands; ${ }^{13}$ Sint Maartenskliniek, Pharmacy, Ubbergen, Netherlands

Background: Patient-reported outcomes (PROs) on adverse drug reactions (ADRs) are increasingly used in cohort event monitoring (CEM) to obtain a better understanding of patient's real-world experience with drugs. Despite the leading role for patients, little is known about their perspectives on these monitoring systems.

Objectives: To obtain more insight in patients' perspectives on the perceived usefulness, ease of use and attitude toward using the Dutch Biologic Monitor (DBM), and their preferred design for a national drug safety monitoring system for immune-mediated inflammatory diseases (IMIDs).

Methods: We developed a cross-sectional open survey following the rationale of the Technology Acceptance Model to obtain insight in patients' perspectives on the DBM. The DBM is a pilot for a PRO-based drug safety monitoring system focused on ADRs attributed to biologics that are prescribed for IMIDs. This survey consisted of 20 categorical and 1 open-ended question. Seven categorical questions contained a text field for additional comments. Five-point Likert-type scales or multiple-choice questions were used to identify patients' preferences and perspectives. Patients were eligible for the survey if they were still enrolled in the DBM at the time of the survey opening and if they had completed at least one questionnaire of the DBM. Categorical questions were descriptively analyzed, whereas text fields were analyzed using theoretical thematic analysis.

Results: At the start of the survey a total of 1,225 patients had participated in the DBM. Approximately $70 \%$ had an inflammatory rheumatic disease. The survey was completed by 292 eligible respondents (response rate $44.8 \%$ ). The respondents generally agreed that it was useful to participate in the DBM and would recommend it to their peers (Figure 1). The response burden of the bimonthly questionnaires was scored as 'low', irrespective of the presence of ADRs or education level (Table 1). A number of respondents suggested that the questionnaire frequency should be synchronized with the regular hospital visits or the administration schedule of the biologic. Moreover, questionnaires should be offered less frequent and preferably shortened in case of an unaltered situation or absence of ADRs. Half $(49.0 \%)$ of the respondents was interested in sharing their questionnaires with a medical specialist, whereas a third $(34.2 \%)$ advocated sharing the questionnaires with their pharmacist (Figure 1).

Table 1. Perceived response burden of the Dutch Biologic Monitor questionnaires. The average burden is calculated using a five-point Likert-type scale. Data is represented as the number of respondents $(n)$.

\begin{tabular}{|c|c|c|c|c|c|c|c|c|c|c|c|}
\hline \multirow[b]{3}{*}{ Burden } & & & \multicolumn{6}{|c|}{ ADRs reported } & \multicolumn{3}{|c|}{ Education level $^{\mathrm{a}}$} \\
\hline & \multicolumn{2}{|c|}{$\begin{array}{l}\text { Overall } \\
(\mathrm{n}=292)\end{array}$} & \multicolumn{2}{|c|}{$\begin{array}{c}\text { Yes } \\
(n=225)\end{array}$} & \multicolumn{2}{|c|}{$\begin{array}{c}\text { No } \\
(n=54)\end{array}$} & \multicolumn{2}{|c|}{$\begin{array}{l}\text { Do not } \\
\text { know } \\
(n=13)\end{array}$} & \multicolumn{2}{|c|}{$\begin{array}{l}\text { Lower } \\
(\mathrm{n}=149)\end{array}$} & $\begin{array}{l}\text { Higher } \\
(\mathrm{n}=139)\end{array}$ \\
\hline & $\mathrm{n}$ & $(\%)$ & $\mathrm{n}$ & $(\%)$ & $\mathrm{n}$ & $(\%)$ & $\mathrm{n}$ & (\%) & $\mathrm{n}$ & $(\%)$ & $(\%)$ \\
\hline 1: No bu & 224 & (76.7) & 169 & (75.1) & 46 & $(85.2)$ & 9 & $(69.2)$ & 106 & $(71.1)$ & $115(82.7)$ \\
\hline 2: Low burd & 58 & (19.9) & 48 & (21.3) & 7 & (13.0) & 3 & (23.1) & 36 & (24.2) & $22(15.8)$ \\
\hline jurden & 6 & $(2.1)$ & 6 & $(2.7)$ & 0 & $(0.0)$ & 0 & $(0.0)$ & 4 & $(2.7)$ & $2 \quad(1.4)$ \\
\hline 4: High & 0 & $(0.0)$ & 0 & $(0.0)$ & 0 & $(0.0)$ & 0 & $(0.0)$ & 0 & $(0.0)$ & $0 \quad(0.0)$ \\
\hline & 0 & $(0.0)$ & 0 & $(0.0)$ & 0 & $(0.0)$ & 0 & $(0.0)$ & 0 & $(0.0)$ & $\begin{array}{ll}0 & (0.0)\end{array}$ \\
\hline No opinion & 4 & (1.4) & 2 & $(0.9)$ & 1 & (1.9) & . & $(0.0)$ & 3 & $(2.0)$ & $(0.0)$ \\
\hline Average burden & & 1.2 & & 1.3 & & 1.1 & & 1.2 & & 1.3 & 1.2 \\
\hline
\end{tabular}

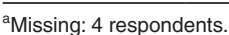

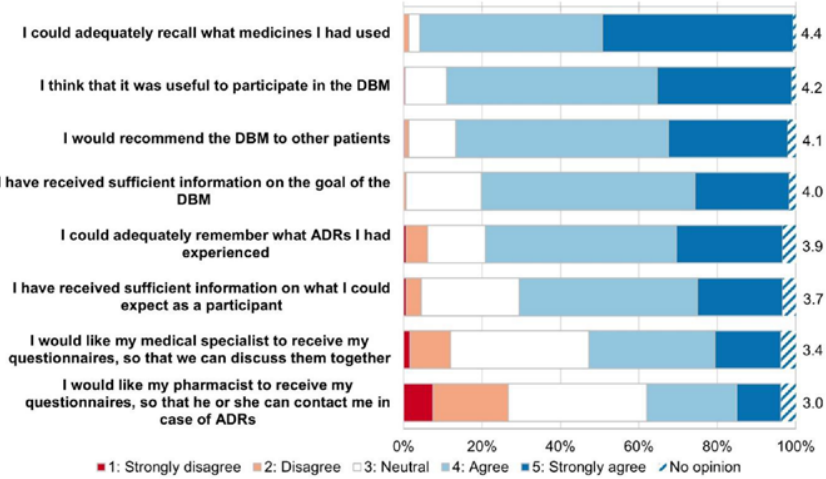

Figure 1. Stacked bar graph of user perspectives. Agreement scores were measured using a five-point Likert-type scale. The average agreement score per statement is indicated on the far right. The percentages represent the share of respondents. DBM: Dutch Biologic Monitor; ADRs: adverse drug reactions.

Conclusion: This study provides valuable insights in the patient perspective on a PRO-based drug safety monitoring system for inflammatory rheumatic diseases and other IMIDs, and provides several useful starting points to further stimulate and improve PRO-based CEM systems. Altogether, it appears feasible to establish a PRO-based drug safety monitoring system that monitors IMID patients' real-world experience with ADRs that has a low burden for the participants.

Disclosure of Interests: Leanne Kosse: None declared, Gerda Weits: None declared, Harald Vonkeman Grant/research support from: AbbVie, Amgen, AstraZeneca, BMS, Celgene, Celltrion, Galapagos, Gilead, GSK, Janssen-Cilag, Lilly, MSD, Novartis, Pfizer, Roche, Sanofi-Genzyme, all outside the submitted work., Sander Tas Grant/research support from: AbbVie, Arthrogen, AstraZeneca BMS, Celgene, Galapagos, GSK, MSD, Pfizer, Roche, Sanofi-Genzyme, all outside the submitted work., Frank Hoentjen Speakers bureau: Abbvie, Jans sen-Cilag, MSD, Takeda, Celltrion, Teva, Sandoz and Dr Falk, all outside the submitted work, Consultant of: Celgene, Janssen-Cilag, all outside the submitted work, Grant/research support from: Dr Falk, Janssen-Cilag, Abbvie, Takeda, all outside the submitted work, Martijn van Doorn Grant/research support from: Leopharma, Novartis, Abbvie, BMS, Celgene, Lilly, MSD, Pfizer, Sanofi-Genzyme, Janssen Cilag, outside the submitted work., Phyllis Spuls Grant/research support from: Departmental independent research grant for TREAT NL registry from different companies, is involved in performing clinical trials with many pharmaceutical industries that manufacture drugs used for the treatment of e.g. psoriasis and atopic dermatitis, for which financial compensation is paid to the department/hospital and, is Chief Investigator $(\mathrm{Cl})$ of the systemic and phototherapy atopic eczema registry (TREAT NL) for adults and children and one of the main investigators of the SECURE-AD registry, all outside the submitted work., Geert D'Haens Consultant of: Abbvie, Ablynx, Active Biotech AB, Agomab Therapeutics, Allergan, Alphabiomics, Amakem, Amgen, AM Pharma, Applied Molecular Therapeutics, Arena Pharmaceuticals, AstraZeneca, Avaxia, Biogen Bristol Meiers Squibb/Celgene, Boehringer Ingelheim, Celltrion, Cosmo, DSM Pharma, Echo Pharmaceuticals, Eli Lilly, Engene, Exeliom Biosciences, Ferring, DrFALK Pharma, Galapagos, Genentech/Roche, Gilead, Glaxo Smith Kline, Gossamerbio, Pfizer, Immunic, Johnson and Johnson, Kintai Therapeutics, Lycera, Medimetrics, Takeda, Medtronic, Mitsubishi Pharma, Merck Sharp Dome, Mundipharma, Nextbiotics, Novonordisk, Otsuka, Photopill, ProciseDx, Prodigest, Prometheus laboratories/Nestle, Progenity, Protagonist, RedHill, Robarts Clinical Trials, Salix, Samsung Bioepis, Sandoz, Seres/Nestec/Nestle, Setpoint, Shire, Teva, Tigenix, Tillotts, Topivert, Versant and Vifor, all outside the submitted work, Michael Nurmohamed Speakers bureau: AbbVie, Celgene, Celltrion, Eli Lilly, Janssen, Sanofi, all outside the submitted work, Consultant of: AbbVie Bristol-Myers Squibb, Eli Lilly, Roche, Sanofi, all outside the submitted work, Grant/research support from: AbbVie, Bristol-Myers Squibb, Celgene, Eli Lilly, Janssen, MSD, Mundipharma, Novartis, Pfizer, Roche, Sanofi, all outside the submitted work, Eugène van Puijenbroek: None declared, Bart van den Bemt: None declared, Naomi Jessurun: None declared DOI: 10.1136/annrheumdis-2021-eular.635

\section{POS0272-HPR POOR RESPONSE TO TKA: THE PERSPECTIVE OF PATIENTS AND KNEE SPECIALISTS}

M. Te Molder ${ }^{1}$, J. Vriezekolk2, J. M. H. Smolders ${ }^{3}$, S. Van Onsem ${ }^{4,5}$ P. Heesterbeek ${ }^{2}$, C. Van den Ende ${ }^{2}$. ${ }^{1}$ Sint Maartenskliniek, Research Department, Nijmegen, Netherlands; ${ }^{1}$ Sint Maartenskliniek, Research Department, Nijmegen, Netherlands; ${ }^{3}$ Sint Maartenskliniek, Department of Orthopedics, Nijmegen, Netherlands; ${ }^{4}$ AZ Alma, Department of Orthopaedics 
and Traumatology, Eeklo, Belgium; ${ }^{5}$ Ghent University, Department of Human Structure and Repair, Ghent, Belgium

Background: Although most of the patients after total knee replacement (TKA) report very satisfied outcome scores, there is still a significant proportion of patients that experience persistent knee pain, functional disability or dissatisfaction after TKA because of osteoarthritis (OA). It is difficult to quantify the proportion of patients with poor response to TKA, as different definitions on failure are being used (1). Additionally, patients and surgeons only agree in $36 \%$ on failure of total joint replacement (TJR) (2). This may be caused by different perceptions about concepts underlying poor response to TKA.

Objectives: To explore if patients and knee specialists have different views about relevant concepts reflecting poor response to primary TKA

Methods: A qualitative, multicentre study was performed using semi-structured interviews in Belgium and in the Netherlands. Purposive sampling was used to enrich data variation. Twenty-five patients with knee OA without surgical indications $(\mathrm{N}=2)$, pre- and postoperative patients $(\mathrm{N}=11$ and $\mathrm{N}=12$, respectively) and fifteen knee specialists (orthopedic surgeons $(\mathrm{N}=9)$, physician assistants $(\mathrm{N}=1)$, nurse practitioners $(\mathrm{N}=1)$ and specialized physiotherapists $(\mathrm{N}=4)$ ) were interviewed individually. Conversations were audiotaped, transcribed verbatim, and analysed using a thematic analysis.

Results: Concepts underlying poor response to TKA were: persistent pain, limited knee function, limitations in physical functioning, complications, unmet expectations, unexpected sequelae and dissatisfaction (Figure 1). The concepts persistent pain, limited knee functioning, complications and limited physical functioning were found to underly expectations and/or unexpected sequelae after TKA. Dissatisfaction was considered a overarching concept resulting from unmet expectations and/or unexpected sequelae after TKA (e.g. long-term use of pain medication, continuous awareness of the prosthesis). All seven concepts were identified by both patients and knee specialists although poor knee function was more often described by patients in terms of prosthesis awareness, whereas knee specialists described poor knee function in terms of instability.

Conclusion: Patients and knee specialists identified similar concepts as relevant concepts reflecting poor response to TKA. These results will be used to formulate a uniform definition of poor response to TKA.

REFERENCES:

[1] Te Molder MEM, Smolders JMH, Heesterbeek PJC, Van Den Ende CHM. Definitions of poor outcome after total knee arthroplasty: An inventory review. BMC Musculoskelet Disord. 2020;21(1):1-6.

[2] Singh J, Mehta B, Mirza S, Figgie M, Sculco P, Parks M, et al. When has a knee or hip replacement failed? A patient perspective. J Rheumatol. 2019;47(9):1-18.

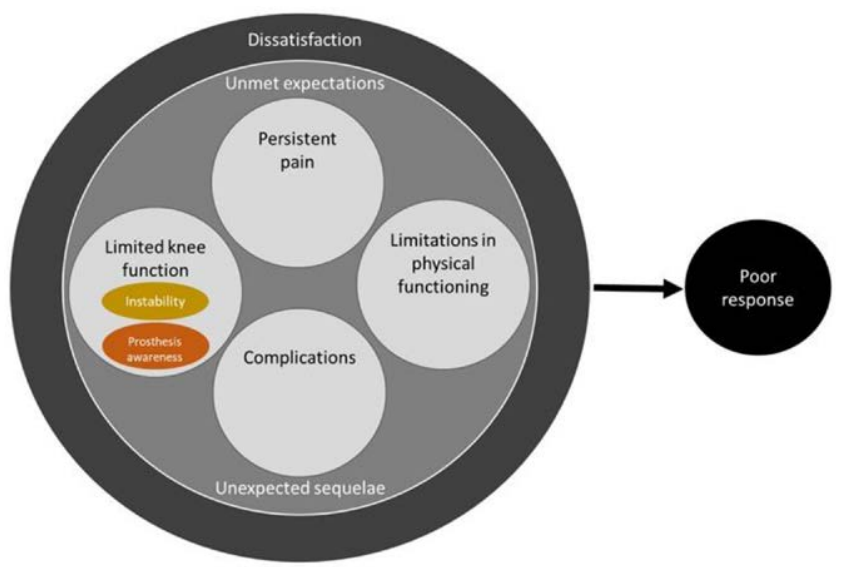

Figure 1. Relevant concepts reflecting poor response to TKA according to the patients' and knee specialists perspectives. Concepts in solid gray were relevant to both, prosthesis awareness was relevant to patients and instability was identified as important outcome by knee specialists.

Disclosure of Interests: None declared

DOI: 10.1136/annrheumdis-2021-eular.2572

\section{POS0273-HPR PHARMACIST'S IMPACT ON SELF-MANAGEMENT FOR PATIENTS WITH CHRONIC INFLAMMATORY ARTHRITIS TREATED WITH BIOLOGICAL DMARDS}

C. Bottois $^{1}$, C. López-Medina ${ }^{2}$, S. Dumas ${ }^{1}$, H. Julien ${ }^{1}$, B. Sephora ${ }^{1}$, C. Roux ${ }^{2}$, A. Moltó ${ }^{2}$, O. Conort ${ }^{1}$, M. Dougados ${ }^{2} .{ }^{1}$ Hôpitaux Universitaire Paris Centre - Site
Cochin, Clinical Pharmacy, Paris, France; ${ }^{2}$ Hôpitaux Universitaire Paris Centre Site Cochin, Rheumatology, Paris, France

Background: Knowledge about chronic inflammatory rheumatisc diseases and skills to administer and manage subcutaneous (subcut) biological DMARDs (bDMARDs) are key aspects to optimize patient's self-management. Intervention of several successive health professionals (e.g comprehensive multidisciplinary team) has proven to be an effective method to improve patient's self-management of their disease and treatment.

Objectives: To assess the pharmacist's impact on patient's knowledge and skills during a multidisciplinary annual review. The secondary objectives were to assess this impact on therapeutic adherence and patient's satisfaction as well as to determine the factors associated with the level of knowledge at baseline. Methods: Study type: prospective, monocentric, 6 months-follow-up, non-controlled study approved by Local Ethical Committee. Inclusion criteria: patien with either rheumatoid arthritis (RA) or spondyloarthritis ( $\mathrm{SpA}$ ), and treated with subcut bDMARDs. Intervention: The visit with a pharmacist evaluating and discussing patient's knowledge and treatment adherence. At baseline (M0): date of the visit and, 3 (M3) and 6 months (M6) later, knowledge and adherence were assessed using self-administered questionnaires: Biosecure and CQR-5 respectively. A questionnaire was sent at $M 3$ in order to evaluate the patient satisfaction. Endpoints: Primary: Changes in Biosecure score Secondary: Percentage of patients with high level of knowledge (score $>84$ ) and percentage of patients with high adherence at M3 and M6; patient's satisfaction; identification of patient's factors (socio-demographics, rheumatisc disease treatments) associated with different levels of knowledge at baseline.

Statistical analysis: repeated measures ANOVA, Bonferroni and Generalized Estimating Equation, univariate and multivariate linear regression.

Results: The study was conducted from October 2019 to July 2020; 79 patients were included (age (years) $=50 \pm 15$; sex ratio $=1.1 ; R A=25, S p A=54)$. The Biosecure scores changed from $71 \pm 18$ to $82 \pm 15(M 3)$ and to $84 \pm 14(M 6)(p<0.001)$. A $\mathrm{M} 0, \mathrm{M} 3$ and $\mathrm{M} 6$, the rate of patients with a high level of knowledge was $24.1 \%$, $59.5 \%$ and $63.3 \%$ respectively $(p<0.001)$. No difference was observed for the change in the $92 \%$ of patients considered as high adherent $(92 \%$ versus $95 \%$ at $\mathrm{MO}$ and $\mathrm{M} 6$ respectively; $\mathrm{p}=0.077$ ). Patient's satisfaction regarding the pharmaceutical intervention was $25 \pm 3(\max =28)$.

Factors associated with a better Biosecure score in the multivariate analysis were the following, lifestyle as a couple $(p<0.001)$, information given by a nurse $(p=0.033)$, information searched for on patient associations $(p=0.013)$ and a low Charlson score $(p=0.001)$

Conclusion: Pharmacist's intervention in the comprehensive multidisciplinary annual review resulted in a beneficial impact on patients' knowledge and skills to manage their bDMARDs with a high level of satisfaction from a patient perspective.

Disclosure of Interests: None declared

DOI: 10.1136/annrheumdis-2021-eular.2135

\section{POS0274-HPR BARRIERS TO PHYSICAL ACTIVITY COLLECTED BY THE IFAB QUESTIONNAIRE CORRELATE WITH LEVELS OF PHYSICAL ACTIVITY IN PATIENTS WITH RHEUMATOID ARTHRITIS OR SPONDYLOARTHRITIS: A CROSS-SECTIONAL STUDY OF 150 PATIENTS}

T. Davergne $^{1}$, R. Tekaya ${ }^{2}$, C. Deprouw ${ }^{3}$, J. Sellam $^{3}$, A. Tournadre ${ }^{4}$,

S. Mitrovic ${ }^{5}$, A. Ruyssen-Witrand ${ }^{6}$, C. Hudry ${ }^{7}$, S. Dadoun ${ }^{8}$, J. Avouac ${ }^{9}$,

B. Fautrel ${ }^{10}$, L. Gossec ${ }^{10}$. 'Sorbonne Université, INSERM, Institut Pierre Louis d'Épidémiologie et de Santé Publique, PEPITES, Paris, France; ${ }^{2} \mathrm{Hôpital}$ Charles Nicolle, University of Tunis El Manar, Rheumatology Department, Tunis, Tunisia; ${ }^{3}$ Saint-Antoine hospital, Rheumatology Department, Paris, France; ${ }^{4}$ Clermont Ferrand hospital, University of Clermont, Rheumatology Department, Clermont Ferrand, France; ${ }^{5}$ Institut Mutualiste Montsouris, Internal Medicine Department, Paris, France; ${ }^{6}$ Purpan hospital, Rheumatology Department, Toulouse, France; ${ }^{7}$ CeSOA, MGEN, Paris, France; ${ }^{8}$ Clinique Geoffroy Saint Hilaire, Ramsay, Paris, France; ${ }^{9}$ Université de Paris, Cochin hospital, Rheumatology Department, Paris, France; ${ }^{10}$ Pitié Salpêtrière hospital, APHP Rheumatology Department, Paris, France

Background: Physical activity is important for patients with inflammatory arthritis (IA), such as spondyloarthritis (axSpA), rheumatoid arthritis (RA) or psoriatic arthritis (PsA). They are more prone to physical inactivity but derive specific benefits from regular physical activity $(1,2)$. It is not easy to modify physical activity level (3). Barriers and facilitators to physical activity can be assessed through questionnaires (4), however, it is important to demonstrate a link between these explanatory elements and physical activity levels.

Objectives: To measure the correlation between barriers and facilitators to physical activity, assessed through a simple questionnaire, and self-reported physical activity levels. 